\title{
Optimization of daily operation mode of photovoltic systems of enterprises
}

\author{
Tulkin Gayibov ${ }^{*}$, and Elnur Abdullaev ${ }^{2}$ \\ ${ }^{1}$ Tashkent State Technical University, Tashkent, Uzbekistan \\ ${ }^{2}$ Djizak Polytechnic Institute, Djizak, Uzbekistan
}

\begin{abstract}
At present, one of the most important issues at the level of various manufacturing enterprises is the development of ways for building and efficiently using renewable energy sources, especially solar energy. In this regard, this article proposes a mathematical model of the problem of determining the optimal daily mode of operation of a photovoltaic system in an enterprise with a private photovoltaic system connected to the electrical system. The effectiveness of the mathematical model was analyzed on the example of determining the optimal mode of operation of the photovoltaic system located on the territory of Jizzakh Polytechnic Institute. It is shown that the mathematical model can be used to determine the optimal operating modes of existing photovoltaic systems in enterprises and distribution networks, as well as to determine the optimal parameters in their design.
\end{abstract}

\section{Introduction}

Today, the sharp increase in energy demand in the world and the corresponding decrease of fuel reserves have made the use of renewable energy sources one of the most important issues. In addition, the significant damage to the environment caused by the use of fossil fuels is one of the key factors determining the efficiency of the use of renewable energy sources. Therefore, at present, several works are being carried out in the Republic of Uzbekistan on the construction and operation of solar power systems using renewable energy sources. Effective construction and operation of such devices require the determination of their optimal parameters in advance based on the use of appropriate mathematical models and algorithms.

In recent years, many publications on the development of photovoltaic power generation technologies, their rational use, and their optimal integration into power systems have appeared. They are important for the development of research and practical work in this area. However, the methods and algorithms for determining the optimal parameters of photovoltaic plants taking into account all the influencing and limiting factors, cannot be considered sufficiently developed. One of the problems is determining the optimal load schedule for a power system for consumers with a private photovoltaic system.

* Corresponding author: tulgayibov@gmail.com 
Today, photovoltaic devices that generate electricity from solar energy are widely introduced in many enterprises worldwide. The capacity of a photovoltaic solar station can be determined depending on the solar radiation in the area, the ambient temperature, and the specific characteristics of the module as follows [1]:

$P_{0}(s)=N \cdot k \cdot U_{y} \cdot I_{y}$
Here: $\quad k=\frac{U_{\max } \cdot I_{\max }}{U_{n l} \cdot I_{s h}} \quad I_{y}=s \cdot\left[I_{s h}+k_{A} \cdot\left(T_{\bmod }-25\right)\right] T_{\text {cell }}=T_{A}+s\left(\frac{{ }_{\text {cell.n }}-20}{0.8}\right)$

$N$ is number of modules; $s$ is solar radiation level; $U_{n l}$ is no-load voltage; $I_{s h}$ is shortcircuit current; $k$ is filling coefficient; $k_{V}$ is voltage coefficient; $k_{A}$ is current coefficient; $T_{\text {mod }}$ is modul temperature; $T_{A}$ is ambient temperature; $T_{\text {cell }}$ is cell temperature; $T_{\text {cell.n }}$ is nominal operating temperature for each cell.

In such photovoltaic systems, the batteries can be used to ensure an uninterrupted power supply [2-4]. On the other hand, the use of batteries can lead to a sharp increase in the cost of construction and operation of photovoltaic plants. Therefore, the necessity of using batteries in such devices is determined based on solving the relevant optimization problems $[2,3,5,6,7]$.

Under the current conditions, enterprises will also be connected to the power grid to use the photovoltaic plant wisely, increase the reliability of the power supply and choose economically viable options. Given the fact that the definition of energy received from the power system varies throughout the day, the company should develop its own optimal daily load schedule. The decision of such a problem in general cases requires solving the problem of optimization, taking into account the simple, functional, and integral constraints in the form of equality and inequality.

An analysis of available literature shows that there are no rigid methods and algorithms for solving such problems based on the use of appropriate mathematical models. [4] considered the problem of optimization of an autonomous power supply system based on solar and wind energy. In [5, 6] proposed the mathematical models and methods for solving the problem of optimization of the location and parameters of battery-powered solar photovoltaic power plants in distribution networks. However, using them directly to effectively solving the problem discussed in this article poses relevant challenges. In [8] described an algorithm for optimization of consumer load schedules, provided that it is possible to regulate loads at individual intervals over a given period without changing the amount of electricity required for that period. It can only be used to solve a problem in special cases. Therefore, developing a mathematical model and algorithm for solving the problem of optimization of consumer load schedules with own power plants operating on renewable energy sources, taking into account all the influencing and limiting factors, remains an important task [9].

Below a mathematical model of the problem of optimization of the daily load schedule of an enterprise with a photovoltaic plant and its solution algorithm are proposed.

\section{Methods}

In addition to the solar modules that generate electricity, the photovoltaic plant installed in enterprise includes additional equipment such as power control devices (controllers) generated at the photovoltaic station, inverters, a monitoring system monitors the parameters of the station operation mode. This equipment can also include batteries for the rational use of generated electricity. Figure 1 shows a schematic diagram of a consumer with a photovoltaic station connected to an electric power system (EPS). 


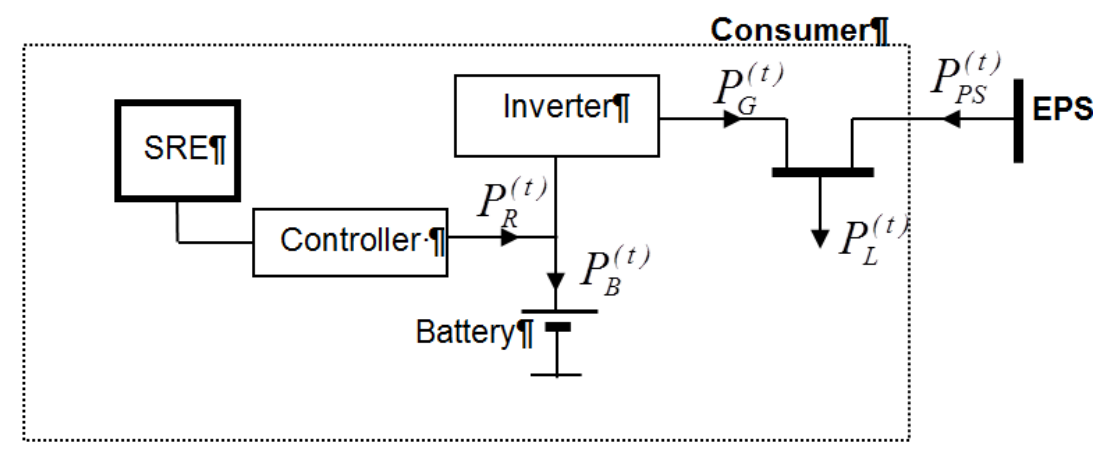

Fig. 1. Schematic diagram of a consumer with own station using renewable energy

In solving this problem, the electric capacity of the battery $\mathrm{W}$, the consumer load schedule $P_{L}(t)$ for the planned day, the power schedule produced at the photovoltaic station $P_{R}(t)$, the minimum and maximum limit charging powers of the battery (corresponding to the negative discharge capacity) are known data. The power schedule of the consumer photovoltaic station $P_{G}(t)$ is determined by solving the optimization problem $P_{G}(t)$, the consumer load schedule $P_{P S}(t)$ relative to the EPS, and the battery charging/discharging power schedule $P_{B}(t)$ is determined as a result of solving the optimization problem.

The objective function is a function of the costs associated with generating electricity by photovoltaic plant and EPS during the day, which should be minimized:

$$
3=\sum_{t=1}^{24}\left[C_{t} P_{P S}^{(t)}+\beta P_{G}^{(t)}\right] \rightarrow \min
$$

Here $C_{t}$ is a unit cost of energy received from the system;

$P_{\mathrm{PS}}^{(\mathrm{t})}$ is an active power from power system;

$P_{\mathrm{G}}^{(\mathrm{t})}$ is an active power generated by photovoltaic plant;

$\beta$ is specific cost of electricity generated by photovoltaic plant, which includes operating costs [10].

Boundary conditions include:

- active power balance in enterprise for each hour of the day:

$$
P_{P S}^{(t)}+P_{G}^{(t)}=P_{L}^{(t)}, \quad t=1,2, \ldots, 24
$$

- the condition that for each hour of the day, the power of the photovoltaic plant is equal to the sum of power consumed to charge the battery and power output from the inverter, ie

$$
P_{R}^{(t)}-P_{B}^{(t)}=P_{G}^{(t)}, \quad t=1,2, \ldots, 24
$$

- the limit condition for the maximum possible charge/discharge capacity of the battery (negative sign means the discharge power):

$$
-P_{B . \max } \leq P_{B}^{(t)} \leq P_{B . \max }, \quad t=1,2, \ldots, 24
$$


- inequality on the minimum and maximum power that can be produced every hour of the day (determined by the power of inverter):

$$
0 \leq P_{G}^{(t)} \leq P_{G . \max }^{(t)}, \quad t=1,2, \ldots, 24 .
$$

- inequality in the energy capacity of the battery:

$$
W_{b a l}+\sum_{k=1}^{t-1}\left[P_{R}^{(k)}-P_{G}^{(k)}\right] \leq W, \quad t=2,3, \ldots, 24
$$

- inequality on the ability to charge and discharge of battery every hour of the day:

$$
-P_{B}^{(t)} \leq W_{b a l}+\sum_{k=1}^{t-1}\left[P_{R}^{(k)}-P_{G}^{(k)}\right] \leq W-P_{B}^{(t)}, \quad t=2,3, \ldots, 24
$$

Here: $P_{R}^{(t)}$ is active power generated by photovoltaic plant at $t$ th hour of the day; $P_{L}^{(t)}$ is total active load of consumers (enterprise) at $t$ th hour of the day; $P_{B . \max }$ is the maximum possible charging (or discharging) capacity of the battery; $P_{G . \max }^{(t)}$ is the maximum power that can be produced for consumption in $t$ th hour of the day; $W$ is electric capacity of the battery; $W_{b a l}$ is electricity remaining in the battery from the previous day.

In this model, the specific cost, which depends on the operating costs of electricity generated by the photovoltaic plant, is assumed to be constant regardless of the power generated.

Since the objective function and all boundary conditions are linear in nature, the optimization problem based on the formed mathematical model can be solved using the linear programming method - the simplex method.

\section{Results and Discussions}

The efficiency of the proposed mathematical model and algorithm for solving the problem under consideration were researched on the example of optimization of loading schedule of Jizzakh Polytechnic Institute, which has a private photovoltaic power plant using solar energy. Table 1 shows the load schedule of the consumer and the daily capacity of the photovoltaic plant and changes in electricity tariffs during the day. The electric capacity of the battery is $\mathrm{W}=24 \mathrm{kWh}$. Residual energy from the previous day in the battery $\mathrm{W}_{\mathrm{bal}}=0$. Maximum charging/discharging capacity of battery $\mathrm{P}_{\mathrm{B}, \max }=4 \mathrm{~kW}$. The unit cost of electricity generated by a private photovoltaic plant is $b=0.088 \$ / \mathrm{kWh}$ when all costs are taken into account. 
Table 1. Consumer daily load schedule and power output schedule of the photovoltaic plant

\begin{tabular}{|c|c|c|c|c|c|c|c|c|}
\hline$t, h$ & 1 & 2 & 3 & 4 & 5 & 6 & 7 & 8 \\
\hline$P_{L}^{(t)}, k W$ & 45.0 & 45.0 & 45.0 & 45.0 & 45.0 & 45.0 & 45.0 & 60.0 \\
\hline$P_{R}^{(t)}, k W$ & 0.0 & 0.0 & 0.0 & 0.0 & 0.0 & 0.0 & 2.0 & 3.0 \\
\hline$C_{t}, \$ / k W h$ & 0.09 & 0.09 & 0.09 & 0.09 & 0.09 & 0.09 & 0.09 & 0.12 \\
\hline$t, h$ & 9 & 10 & 11 & 12 & 13 & 14 & 15 & 16 \\
\hline$P_{L}^{(t)}, k W$ & 155.0 & 160.0 & 160.0 & 160.0 & 160.0 & 160.0 & 160.0 & 160.0 \\
\hline$P_{R}^{(t)}, k W$ & 3.5 & 4.0 & 4.5 & 5.0 & 6.0 & 6.0 & 6.0 & 5.0 \\
\hline$C_{t}, \$ / k W h$ & 0.12 & 0.12 & 0.12 & 0.12 & 0.12 & 0.12 & 0.12 & 0.12 \\
\hline$t, h$ & 17 & 18 & 19 & 20 & 21 & 22 & 23 & 24 \\
\hline$P_{L}^{(t)}, k W$ & 125.0 & 180.0 & 185.0 & 180.0 & 105.0 & 65.0 & 40.0 & 30.0 \\
\hline$P_{R}^{(t)}, k W$ & 4.0 & 3.5 & 3.0 & 2.0 & 0.0 & 0.0 & 0.0 & 0.0 \\
\hline$C_{t}, \$ / k W h$ & 0.14 & 0.14 & 0.14 & 0.14 & 0.14 & 0.12 & 0.09 & 0.09 \\
\hline
\end{tabular}

Table 2 and Figure 2 the optimization results using the proposed model and the selected optimization method (Gurobi), i.e., the optimal schedules of active power from the photovoltaic plant $P_{G}(t)$ and the active power from the power system $P_{P S}(t)$, as well as the optimal battery charge $P_{c h}(t)$ or discharge $P_{d c h}(t)$ are given. Here, the charging capacity of the battery is positive, and the discharging capacity is negative. The total daily cost of electricity from a photovoltaic plant and power system is $\$ 308,705$.

Table 2. Optimal daily load charts in the case where the photovoltaic station has a battery.

\begin{tabular}{|c|c|c|c|c|c|c|c|c|}
\hline$t, h$ & 1 & 2 & 3 & 4 & 5 & 6 & 7 & 8 \\
\hline$P_{L}^{(t)}, \mathrm{kW}$ & 45.0 & 45.0 & 45.0 & 45.0 & 45.0 & 45.0 & 45.0 & 60.0 \\
\hline$P_{P S}^{(t)}, \mathrm{kW}$ & 45.0 & 45.0 & 45.0 & 45.0 & 45.0 & 45.0 & 45.0 & 57.0 \\
\hline$P_{R}^{(t)}, \mathrm{kW}$ & 0 & 0 & 0 & 0 & 0 & 0 & 2.0 & 3.0 \\
\hline$P_{G}^{(t)}, \mathrm{kW}$ & 0 & 0 & 0 & 0 & 0 & 0 & 0 & 3.0 \\
\hline$P_{d c h}^{(t)}, \mathrm{kW}$ & 0 & 0 & 0 & 0 & 0 & 0 & 0 & 0 \\
\hline$P_{c h}^{(t)}, \mathrm{kW}$ & 0 & 0 & 0 & 0 & 0 & 0 & 2.0 & 0 \\
\hline $\begin{array}{c}t, h \\
P_{L}^{(t)}, \mathrm{kW}\end{array}$ & 155.0 & 160.0 & 160.0 & 160.0 & 160.0 & 160.0 & 160.0 & 160.0 \\
\hline$P_{P S}^{(t)}, \mathrm{kW}$ & 155.0 & 160.0 & 155.75 & 155.0 & 158.0 & 154.0 & 154.0 & 159.0 \\
\hline$P_{R}^{(t)}, \mathrm{kW}$ & 3.5 & 4.0 & 4.5 & 5.0 & 6.0 & 6.0 & 6.0 & 5.0 \\
\hline
\end{tabular}


Table 2 continued

\begin{tabular}{|c|c|c|c|c|c|c|c|c|}
\hline$P_{G}^{(t)}, \mathrm{kW}$ & 0 & 0 & 4.25 & 5.0 & 2.0 & 6.0 & 6.0 & 1.0 \\
\hline$P_{d c h}^{(t)}, \mathrm{kW}$ & 0 & 0 & 0 & 0 & 0 & 0 & 0 & 0 \\
\hline$P_{c h}^{(t)}, \mathrm{kW}$ & 3.5 & 4.0 & 0.25 & 0 & 4.0 & 0 & 0 & 4.0 \\
\hline$t, h$ & 17 & 18 & 19 & 20 & 21 & 22 & 23 & 24 \\
\hline$P_{L}^{(t)}, \mathrm{kW}$ & 125.0 & 180.0 & 185.0 & 180.0 & 105.0 & 65.0 & 40.0 & 30.0 \\
\hline$P_{P S}^{(t)}, \mathrm{kW}$ & 118.25 & 173.25 & 178.25 & 174.0 & 101.0 & 65.0 & 40.0 & 30.0 \\
\hline$P_{R}^{(t)}, \mathrm{kW}$ & 4.0 & 3.5 & 3.0 & 2.0 & 0 & 0 & 0 & 0 \\
\hline$P_{G}^{(t)}, \mathrm{kW}$ & 6.75 & 6.75 & 6.75 & 6 & 4 & 0 & 0 & 0 \\
\hline$P_{d c h}^{(t)}, \mathrm{kW}$ & -2.75 & -3.25 & -3.75 & -4.0 & -4.0 & 0 & 0 & 0 \\
\hline$P_{c h}^{(t)}, \mathrm{kW}$ & 0 & 0 & 0 & 0 & 0 & 0 & 0 & 0 \\
\hline
\end{tabular}

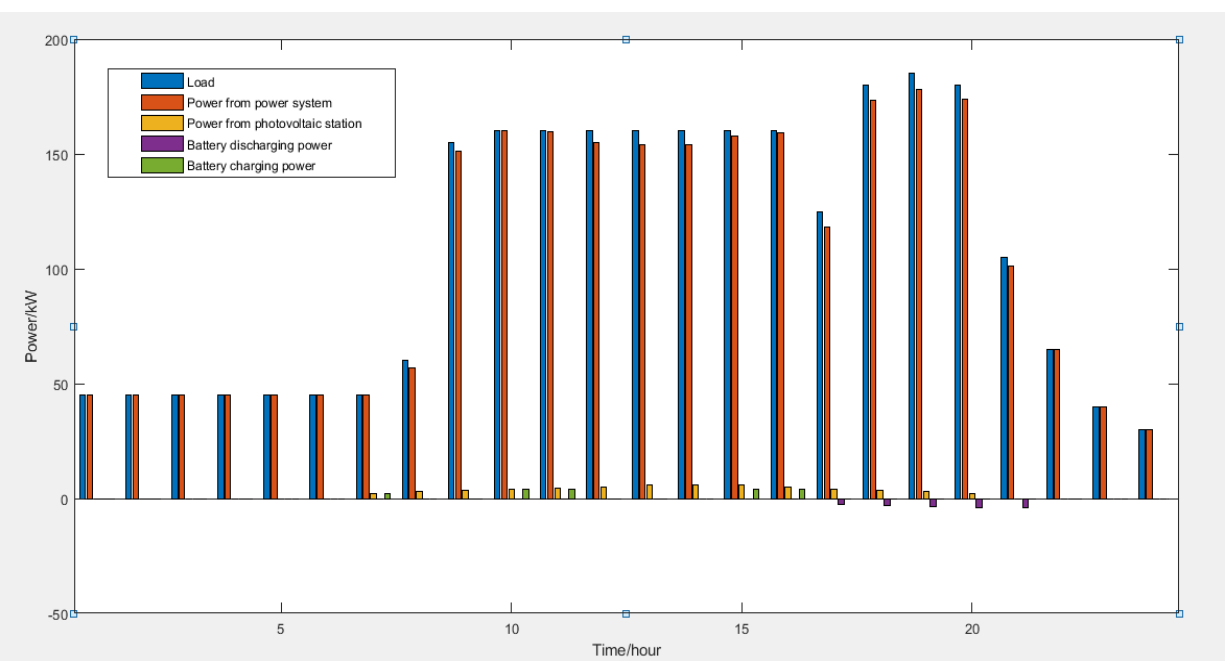

Fig. 2. Daily load diagrams of the consumer, photovoltaic station, and battery.

To compare the optimization results, Table 3 shows the optimization results for the case where the photovoltaic plant does not have a battery. In this case, the daily cost of electricity from the photovoltaic plant and the power system is $\$ 309.12$. 
Table 3. Optimal daily load charts when the photovoltaic station does not have a battery.

\begin{tabular}{|c|c|c|c|c|c|c|c|c|}
\hline$t, h$ & 1 & 2 & 3 & 4 & 5 & 6 & 7 & 8 \\
\hline$P_{L}^{(t)}, \mathrm{kW}$ & 45.0 & 45.0 & 45.0 & 45.0 & 45.0 & 45.0 & 45.0 & 60.0 \\
\hline$P_{P S}^{(t)}, \mathrm{kW}$ & 45.0 & 45.0 & 45.0 & 45.0 & 45.0 & 45.0 & 43.0 & 57.0 \\
\hline$P_{G}^{(t)}, \mathrm{kW}$ & 0 & 0 & 0 & 0 & 0 & 0 & 2.0 & 3.0 \\
\hline$t, h$ & 9 & 10 & 11 & 12 & 13 & 14 & 15 & 16 \\
\hline$P_{L}^{(t)}, \mathrm{kW}$ & 155.0 & 160.0 & 160.0 & 160.0 & 160.0 & 160.0 & 160.0 & 160.0 \\
\hline$P_{P S}^{(t)}, \mathrm{kW}$ & 151.5 & 156.0 & 155.5 & 155.0 & 154.0 & 154.0 & 154.0 & 155.0 \\
\hline$P_{G}^{(t)}, \mathrm{kW}$ & 3.5 & 4.0 & 4.5 & 5.0 & 6.0 & 6.0 & 6.0 & 5.0 \\
\hline$t, h$ & 17 & 18 & 19 & 20 & 21 & 22 & 23 & 24 \\
\hline$P_{L}^{(t)}, \mathrm{kW}$ & 125.0 & 180.0 & 185.0 & 180.0 & 105.0 & 65.0 & 40.0 & 30.0 \\
\hline$P_{P S}^{(t)}, \mathrm{kW}$ & 121.0 & 176.5 & 182.0 & 178.0 & 0 & 0 & 0 & 0 \\
\hline$P_{G}^{(t)}, \mathrm{kW}$ & 4.0 & 3.5 & 3.0 & 2.0 & 0 & 0 & 0 & 0 \\
\hline
\end{tabular}

Thus, in the example considered, optimization of the load schedule of EPS and photovoltaic plants for the consumer with photovoltaic plant in the presence of battery reveals that the total daily cost of electricity is $1.3 \%$ lower than in the absence of a battery. The relatively low efficiency due to battery presence is determined by factors such as the amount of charge and the small size of the photovoltaic power plant, the lack of change in the definition of electricity during the day.

In the example considered, the power schedule produced by the photovoltaic plants was adopted in deterministic form. In general, such schedules may be probabilistic or partially uncertain. Under such conditions, optimization based on the proposed mathematical model and method can be effectively solved based on the use of the algorithms presented in [1114].

\section{Conclusions}

A mathematical model and method for solving the problem of optimization of load schedules of consumers with their own photovoltaic plants were proposed.

It has been shown that significant economic efficiency can be achieved by optimization the consumer's own photovoltaic plant and EPS load schedules in the face of changing the tariff of electricity throughout the day.

The proposed mathematical model and method of optimizing the load schedules of consumers with a private photovoltaic plant can be used to solve the problem of optimal planning of daily loads of enterprises with such plants. The proposed model and method can also be used to select optimal photovoltaic plants' optimal parameters to be installed in the territory of large power consumers. 


\section{References}

1. Duong Quoc Hung, N. Mithulananthan, R.C. Bansal. (2014). Integration of PV and BES units in commercial distribution systems considering energy loss and voltage stability. Applied Energy. 113. 1162-1170.

2. Xing, H., Cheng, H., Zhang, Y. and Zeng, P. (2016). Active distribution network expansion planning integrating dispersed energy storage systems. IET Generation, Transmission \& Distribution. 10(3). 638-644.

3. Padmanabhan, N., Ahmed, M. and Bhattacharya, K. Battery Energy Storage Systems in Energy and Reserve Markets. IEEE Transactions on Power Systems. (2019).

4. Harpreet kaur Channi,Surbhi Gupta,Arvind Dhingra. Optimization and simulation of a solar-wind hybrid system using HOMER for Rural Electrification. International Journal of Advanced Science and Technology, 29(10s), 2108-2116. Retrieved from http://sersc.org/journals/index.php/IJAST/article/view/16821. (2020).

5. Akbari-Dibavar, A., Nojavan, S., Zare, K. (2019). Optimal Sitting and Sizing of Energy Storage Systems in a Smart Distribution Network Considering Network Constraints and Demand Response Program. Journal of Energy Management and Technology, 3(2), 14-25. doi: 10.22109/jemt.2018.143478.111.

6. Rayees Ahmad Thokar, Nikhil Gupta, K R Niazi, Anil Swarnkar, Sachin Sharma, N K Meena. Optimal Integration and Management of Solar Generation and Battery Storage System in Distribution Systems under Uncertain Environment. International Journal of Renewable Energy Research. 10(1), March. (2020).

7. Sterling, G. and Tyler, B. (2018). Renewable Energy Management Using Action Dependent Heuristic Dynamic Programming. IEEE International Smart Cities Conference (ISC2), 1-5. USA. doi: 10.1109/ISC2.2018.8656942.

8. Gayibov, T.Sh., Reymov, K.M., Optimal Planning of Short-Term Modes of Power Systems with Control of Loads of Electric Consumers and Taking into Account of Network Factor. European Science Review. 3(9-10), pp. 86-91. (2017).

9. T.Sh. Gayibov, B.A. Uzakov, E.A. Abdullaev. (2020) Optimization of loading schedules of consumers with own stations on the basis of renewable energy sources. Journal of critical reviews. 7(15) 1738-1742.

10. Jordan Radosavljević, Nebojša Arsić, Miloš Milovanović, and Aphrodite Ktena. (2020). Optimal Placement and Sizing of Renewable Distributed Generation Using Hybrid Metaheuristic Algorithm. Journal of modern power systems and clean energy. 8(3), 499-510.

11. Tulkin Gayibov, Bekzod Pulatov, Sherxon Latipov, Gulnaz Turmanova: Power System Optimization in Terms of Uncertainty of Initial Information. E3S Web of Conference 139, 01031 (2019). RSES 2019. https://doi.org/10.1051/e3sconf/201913901031.

12. T Gayibov, Sh Latipov, D Abdurashidov, B Pulatov, A Davirov: Algorithm for power systems mode optimization taking into account the frequency change in terms of probablistic nature of initial information. IOP Conf. Series: Materials Science and Engineering, 883, 012185 (2020). doi:10.1088/1757-899X/883/1/012185.

13. Tulkin Gayibov. Algorithm for optimization of power system short-term mode in conditions of partial uncertainty of initial information taking into account the frequency change. E3S Web of Conference 216, 01100 (2020). RSES 2020. https:/doi.org/10/1051le3sconf/202021601100.

14. Valdma M, Keel M, Liik O and Tammoja H.: Method of Minimax optimization of Power System Operation. In: Bologna Italy Proccedings of IEEE Bologna Power Tech. pp. 23-26 (2003). 